\title{
When Wine and Apple Both Help the Production of Grapes: ERP Evidence for Post-lexical Semantic Facilitation in Picture Naming
}

\author{
Grégoire Python*, Raphaël Fargier and Marina Laganaro \\ Faculty of Psychology and Educational Science, University of Geneva, Geneva, Switzerland
}

OPEN ACCESS

Edited by:

Xiaolin Zhou,

Peking University, China

Reviewed by:

Guido Gainotti, Università Cattolica del Sacro Cuore,

Zhen Yut

Italy

University of Macau, China

*Correspondence: Grégoire Python gregoire.python@unige.ch

Received: 11 December 2017 Accepted: 26 March 2018 Published: 10 April 2018

Citation:

Python G, Fargier R and Laganaro $M$ (2018) When Wine and Apple Both Help the Production of Grapes: ERP Evidence for Post-lexical Semantic Facilitation in Picture Naming.

Front. Hum. Neurosci. 12:136. doi: 10.3389/fnhum.2018.00136
Background: Producing a word in referential naming requires to select the right word in our mental lexicon among co-activated semantically related words. The mechanisms underlying semantic context effects during speech planning are still controversial, particularly for semantic facilitation which investigation remains under-represented in contrast to the plethora of studies dealing with interference. Our aim is to study the timecourse of semantic facilitation in picture naming, using a picture-word "interference" paradigm and event-related potentials (ERPs).

Methods: We compared two different types of semantic relationships, associative and categorical, in a single word priming and a double word priming paradigm. The primes were presented visually with a long negative Stimulus Onset Asynchrony (SOA), which is expected to cause facilitation.

Results: Shorter naming latencies were observed after both associative and categorical primes, as compared to unrelated primes, and even shorter latencies after two primes. Electrophysiological results showed relatively late modulations of waveform amplitudes for both types of primes (beginning $\sim 330$ ms post picture onset with a single prime and $\sim 275$ ms post picture onset with two primes), corresponding to a shift in latency of similar topographic maps across conditions.

Conclusion: The present results are in favor of a post-lexical locus of semantic facilitation for associative and categorical priming in picture naming and confirm that semantic facilitation is as relevant as semantic interference to inform on word production. The post-lexical locus argued here might be related to self-monitoting or/and to modulations at the level of word-form planning, without excluding the participation of strategic processes.

Keywords: semantic facilitation, semantic priming, ERP, language production, picture naming, response selection

\section{INTRODUCTION}

In everyday conversations, we choose effortlessly the right words in our vast mental lexicon to communicate the meaning we intend to. Most serial models of speech production consider that the spread of activation from conceptual (pre-lexical) representations to lexical selection is semantically driven. In that context, lexical selection is seen as a decisional process, during which we have to select the right "target" word among other semantically related "non-target" words. These co-activated non-target words can either create a facilitatory or an inhibitory context, 
respectively speeding up or slowing down speech planning (Roelofs, 1992, 2006; Chen and Mirman, 2012). In language production research, semantic interference effects (i.e., word production slowed down by an inhibitory semantic context) have received a lot of interest. They have been mainly studied with the Stroop task (for an integrative review, see MacLeod, 1991) and its variant, the picture-word interference paradigm (PWIP), in which pictures instead of colors are used and the asynchrony of the picture-word pair presentation is manipulated (for the first description of a PWIP, see Rosinski et al., 1975). Contrasting with the plethora of studies dealing with interference, only a few investigations adressed semantic facilitation effects (for a discussion, see Mahon et al., 2007); and yet, "natural" semantic contexts seem to be generally facilitative rather than interfering, as it is usually shown in semantic categorization tasks (Kuipers and La Heij, 2008; Hantsch et al., 2012), semantic priming tasks in speech perception (Lucas, 2000) and picture naming after a constraining sentential context (Griffin and Bock, 1998; Piai et al., 2014b, 2015). Psycholinguistic studies may actually have focused too much on interfering semantic effects, i.e., on the exception that proves the rule. In that sense, Mahon et al. (2007, p. 505) argued "that the critical data that should inform models of lexical selection are semantic facilitation effects" and not (only) interference effects.

In the PWIP, semantic interference and facilitation effects are defined as a difference of mean latencies when naming a picture in two experimental conditions: a semantic-high condition (usually a word from the same category as the target picture) and a semantic-low condition (a word unrelated with the target picture). Semantic interference in the PWIP has been typically obtained with a semantic-high condition consisting of coordinates (e.g., pear-apple; Rosinski et al., 1975; Rosinski, 1977; Lupker, 1979; La Heij, 1988; La Heij and van den Hof, 1995; Starreveld and La Heij, 1996; Vitkovitch and Tyrrell, 1999; Costa et al., 2005; Finkbeiner and Caramazza, 2006; Sailor et al., 2009; Damian and Spalek, 2014), independently of the strength of the categorical overlap between the picture and the word (Hutson and Damian, 2014). But semantic interference in the PWIP has also been obtained with subordinates (e.g., tulipflower; Hantsch et al., 2005, 2012), superordinates (e.g., birdseagull; Hantsch et al., 2005; Kuipers et al., 2006) and part-terms (e.g., window-car; Sailor and Brooks, 2014). Even if the typical and often described result is interference, the PWIP can just as much induce semantic facilitation, yet under certain experimental conditions. Semantic facilitation in the PWIP has been obtained with a large panel of semantically related words: coordinates (Finkbeiner and Caramazza, 2006), subordinates (Costa et al., 2003), superordinates (Vitkovitch and Tyrrell, 1999; Damian and Abdel Rahman, 2003), associates not being coordinates (e.g., milk-cow; Alario et al., 2000; Costa et al., 2005; Sailor et al., 2009; de Zubicaray et al., 2013; Damian and Spalek, 2014; Sailor and Brooks, 2014), related adjectives (e.g., chilly-ice; Bölte et al., 2013) and related verbs (e.g., sitchair; Mahon et al., 2007). More crucially, some PWIP studies demonstrated that the exact same set of materials used in slighlty different experimental settings can shift the polarity of the effect from interference to facilitation. For instance, the Stimulus
Onset Asynchrony (SOA) seems to play a predominant role: several studies (Glaser and Düngelhoff, 1984; Alario, 2001; Bloem et al., 2004; Zhang et al., 2016) reported semantic interference particularly with near-to-0 SOAs but semantic facilitation with long negative SOAs (from $-400 \mathrm{~ms}$ to $-1000 \mathrm{~ms}$ ). The polarity of the effect can also be affected by the visibility of the primes (Finkbeiner and Caramazza, 2006), the modality of the primes and the rate of congruent responses (Hantsch et al., 2009), and the presence of a familiarization phase (Collina et al., 2013).

The large amount of studies on semantic interference has given rise to different interpretative hypotheses regarding its underlying mechanisms and served to develop models of lexical access. Interfering effects in the PWIP have often been interpreted as reflecting the competition between lexical representations (Schriefers et al., 1990; Levelt et al., 1999; Damian and Bowers, 2003; Howard et al., 2006). Due to lexical competition, the latency of the target word selection "mathematically" depends on the state of activation of the non-target words (Levelt et al., 1999). In other words, it takes longer to select the right lexical representation among a high number of competitors strongly co-activated. However, other models locate the competition process at a pre-lexical stage, via a learning mechanism weakening the semantic-to-lexical connections (Oppenheim et al., 2010) or at a post-lexical stage (Finkbeiner and Caramazza, 2006; Mahon et al., 2007; Janssen et al., 2008). The response-competition (or response-exclusion) hypothesis indeed states that in presence of a picture-word pair, the distractor word is automatically encoded and put in the phonological output buffer and ready to be produced (Lupker, 1979; Roelofs, 2003). The distractor word has to be detected and deleted before being able to produce the target word associated to the picture. The more semantic features are shared between the picture and the interfering word, the more time will be necessary to remove the distractor word from the response buffer. For example, the picture "cat" associated with the word "dog" leads to a very competitive situation, because the overlap of semantic features is high, making the dog a relevant candidate when naming a cat. Consequently, the exclusion of a semantically close potential candidate increases naming latencies in the PWIP. Finally, some authors argue that a general mechanism responsible for checking online the accuracy of speech production, the verbal self-monitoring, becomes more alert in semantic-high conditions, either to suppress the buffered response (Dhooge and Hartsuiker, 2012) or to validate the selection of the target-word in the context of highly activated competitors (Maess et al., 2002; Ganushchak and Schiller, 2008).

As for semantic facilitation effects in the PWIP, they have usually been interpreted as reflecting automatic spreadingactivation from semantically related conceptual representations to their corresponding lexical representations. According to this view, a higher level of activation of the semantic nodes results in faster lexical selection, independently of the non-target words, i.e., without lexical competition (Dell and O'Seaghdha, 1991; Mahon et al., 2007). Similar to semantic interference, other interpretations do not locate the spreading process at the 
lexical level. First, the Conceptual Selection Model (Bloem et al., 2004) claims that the co-activated conceptual representations do not automatically activate their corresponding lexical representations. Therefore, the semantic spreading-activation is restricted to the conceptual/pre-lexical level (Collins and Loftus, 1975), leading to an earlier start of the lexical stage and shorter naming latencies. Second, Starreveld and La Heij (1995, 1996) proposed an interactive activation model accounting for context effects in the PWIP, where semantic and phonological levels are bidirectionnally interconnected, and in which semantic similarity effects are located at the post-lexical level. In this connectionist model, the phonological node of the target receives activation both from the picture and the related word due to the connections at the semantic level.

Although relying on different theoretical backgrounds, semantic interference and facilitation in the PWIP have both been alternately interpreted as pre-lexical, lexical or post-lexical effects. These interpretations have been based mostly on behavioral/offline measures (latencies in the case of picture naming), which might not be precise enough to understand which processing stage is affected. For this purpose, eventrelated potentials (ERPs) have been combined with PWIPs in a few studies to detail the time-course of semantic context effects on single word production. Semantic interference effects were investigated in the framework of lexical competition that seems amplified in the PWIP with near-to-0 ms SOAs. ERP modulations for coordinates (vs. unrelated distractors) were reported starting 230-275 ms (Aristei et al., 2011; Piai et al., 2012; Wong et al., 2017), or 320-350 ms post picture onset (Dell'Acqua et al., 2010; Piai et al., 2014a; Shitova et al., 2016). The $100 \mathrm{~ms}$ discrepancy in the time-windows associated to semantic interference in these studies are hardly compatible with a unique interpretation, all the more that the later time-window (320-350 ms after picture onset) falls much beyond estimates situating lexical selection before $275 \mathrm{~ms}$ (Indefrey, 2011). Two other studies reported semantic interference for coordinates that was rather interpreted as semantic priming, but again effects on ERPs were observed in very different timewindows: either very early, i.e., $106 \mathrm{~ms}$ post picture onset (Dell'Acqua et al., 2010) or quite late, i.e., $325 \mathrm{~ms}$ post picture onset (Blackford et al., 2012). Blackford et al. (2012) provided also an alternative interpretation for their late semantic ERP modulations, namely that they possibly mirrored "activity at the phonological word-form representation". Finally, ERP studies addressing semantic facilitation effects in the PWIP focused on associates: ERP modulations by semantic context started as early as $120 \mathrm{~ms}$ post picture onset (Hirschfeld et al., 2008) or around $200 \mathrm{~ms}$ post picture onset (Aristei et al., 2011), and were interpreted respectively as reflecting a speed-up of object identification or (pre-)lexical processes.

The aforementioned ERP studies investigating the time-course of semantic interference and facilitation in the PWIP reported discrepant results on their time-course and brought forth different interpretations. As summerized above for the behavioral results, some of these discrepancies may be due to the SOA and to the different types of semantic relationships between the word and the picture. To try to shed light on these two variables, the word-picture relationship (associative vs. categorical) was manipulated in the ERP study reported here. We used a long negative SOA to increase the probability of obtaining semantic facilitation effects (Glaser and Düngelhoff, 1984; Alario, 2001; Bloem et al., 2004; Zhang et al., 2016), on a material previously tested with a short negative SOA (see below in the "Materials and Methods" section).

Among the set of variables influencing semantic effects in the PWIP, the number of words presented with the picture has been shown to increase semantic interference. When two categorical words were presented alongside the picture, they slowed down picture naming (Abdel Rahman and Melinger, 2008), which was interpreted as increased competition due to a higher number of activated lexical competitors. To our knowledge, the presentation of two semantically related words in a PWIP has been used only to study semantic interference (Abdel Rahman and Melinger, 2008; Melinger and Abdel Rahman, 2013), but not facilitation. To address this issue, we compared naming responses and their neural correlates when a picture was preceded by one word or by two words (single vs. double priming hereafter). This manipulation of the amount of semantic contextual priming, as well as the type of priming words (associative/categorical) should make a decisive insight to current models of speech production. The present investigation might offer innovative knowledge about word production: semantic facilitation is inherent in everyday conversation, as we always benefit from a given semantic context to produce speech easily. This follows the argument that semantic facilitation in the PWIP (but also in the blocked-cyclic naming paradigm) could be even more natural and more relevant than semantic interference to inform on lexical selection (Mahon et al., 2007; Navarrete et al., 2014).

We predicted that participants would be faster when naming pictures after semantically related primes (associative or categorical), as compared to unrelated primes with long negative SOAs. Early ERP modulations around the P2/N2 component ( 200-250 ms post picture onset) would presumably point to a lexical locus of semantic facilitation, whereas earlier/later modulations to pre-/post-lexical processes respectively. Multiple words should produce more facilitation than a single word if they boost the activation of the target by overcoming lexical competition, or less facilitation if they increase lexical competition in keeping multiple competitors highly active.

\section{MATERIALS AND METHODS}

\section{Participants}

Twenty-four French-speaking and right-handed adults participated in this study (aged 19-24, mean 21.1, one male). They were undergraduate students at the University of Geneva and received course credit for their participation. They all had normal or corrected-to-normal vision. None of them had a significant history of neurological disorder. This study was carried out in accordance with the recommendations of the ethical committee of the Faculty of Psychology and Educational Science of Geneva University for research on healthy subjects ("Etude psycholinguistique de la production 
et compréhension du langage: approches comportementales et électrophysiologiques") with written informed consent from all subjects in accordance with the Declaration of Helsinki. The protocol was approved by the ethical committee on May 16th 2013.

\section{Material}

A set of 59 black and white line drawings (resized to $240 \times$ 245 pixels) were chosen from two databases (Alario and Ferrand, 1999; Bonin et al., 2003). All pictures had a high name agreement in french (above 70\%) and covered 17 different semantic categories (1-13 items per category): food, animals, housekeeping material, trees, weapons, jewels, living places, music instruments, desk material, media, vehicles, tools, body parts, recipients, personal care items, kitchenware, clothes. Each picture/word in this set of 59 stimuli was linked with six words: two associative words, respectively one high-associative word (i.e., more than $14.6 \%$ of the subjects gave this word as the first associate in Ferrand and Alario, 1998) and one low-associative word (i.e., less than $14.6 \%$ in Ferrand and Alario, 1998), two words belonging to the same semantic category (as stated in Bueno and Megherbi, 2009, when semantic category was available) and two unrelated words. Unrelated words corresponded to half of the associative words and half of the categorical words re-paired to match unrelated targets. According to the database Lexique (New et al., 2004), the associative (ASS), categorical (CAT) and unrelated (UNR) words lists were comparable in terms of lexical frequency and length (phonemes/syllables). None of the associative words belonged to the same semantic category as the target to name and all verbs were changed into their derivated common nouns (e.g., to fly-flight). The priming words did not share the same initial or final phonemes with the target to name. The high-associative word or the most frequent categorical word was presented in case of single priming and in first position in case of double priming. An item example is given in Table $\mathbf{1}$ and the entire list of word stimuli can be found in the Supplementary Material.

In total, each target picture appeared six times throughout the experiment, i.e., in three different conditions (ASS, CAT, UNR) and preceded by one or two words (single or double priming). The stimuli presentation order was pseudo-randomized and counterbalanced in twelve different lists, so that the same target pictures were separated by at least 20 other pictures and the condition (ASS, CAT, UNR) was identical for a maximum of two consecutive trials. In each list, the number of primes that preceded the target (i.e., one or two) was randomly mixed.

The material was tested in a preliminary study in which a written single word was presented $66 \mathrm{~ms}$ before the picture to name, in order to assess if it was able to elicit the classical semantic interference effect (at least with coordinates). After a fixation cross (1250 ms onscreen), the word prime was presented

TABLE 1 | Example of prime samples for the target picture "airplane".

\begin{tabular}{llll}
\hline & Associative & Categorical & Unrelated \\
\hline Single priming & Flight & Helicopter & Rope \\
Double priming & Flight, sky & Helicopter, bus & Rope, shovel
\end{tabular}

for $53 \mathrm{~ms}$, and a $13 \mathrm{~ms}$ blank screen preceded the picture (SOA $-66 \mathrm{~ms}$ ) which remained $2000 \mathrm{~ms}$ on screen. The inter-stimulus interval lasted $1000 \mathrm{~ms}$. All other manipulations and behavioral data analyses were the same as in the ERP experiment (see below). Twenty-eight undergraduate students took part in this preliminary study, and did not take part in the ERP experiment (aged 18-35, five males).

As expected, categorical semantic interference was observed with slower reaction times with categorical primes (mean RT $806 \mathrm{~ms}$ ) relative to unrelated primes (mean RT $791 \mathrm{~ms}$; $t_{(4623)}=3.499, p<0.001$ ) and to associative primes (mean RT $\left.785 \mathrm{~ms} ; t_{(4620)}=4.675, p<0.001\right)$, but no difference was found between associative and unrelated primes $\left(t_{(4622)}=1.185\right.$, $p=0.24)$.

\section{Procedure}

Participants sat in a comfortable desk chair in a sound-proof room, approximately $50 \mathrm{~cm}$ in front of a computer screen. They were randomly assigned to one of the 12 counterbalanced lists. Before the experiment, they first underwent a familiarization phase consisting in reading aloud the names written underneath the 59 target pictures. Then, they performed a practice phase consisting in naming the 59 target pictures once, without display of the names. This double pre-exposure was supposed not only to avoid naming errors and hesitations, but also to minimize the repetition priming and the role of object identification during the experiment (Francis, 2014). In these two early phases, they could proceed at their own pace, the pictures being presented one by one on the computer screen in alphabetical order.

As for the task itself, the subjects were instructed to name the pictures as quickly and accurately as possible and there were three warming-up filler trials before beginning the experiment. The trials were presented through E-Prime 2.0 software $^{1}$ (Psychology Software Tools, Pittsburgh, PA, USA) and responses were recorded with an external microphone.

On each trial, a green fixation plus sign (+) appeared in the center of the screen for $250 \mathrm{~ms}$. The plus sign remained on screen until the presentation of the written prime(s): a written word prime was presented in the center of the screen in font Courier New 48 for 554 ms (SOA -700 ms). In case of double priming, the second word prime was presented alike after a blank screen of $150 \mathrm{~ms}$ (SOA $-1400 \mathrm{~ms}$ ). A blank screen was then presented for $150 \mathrm{~ms}$ and finally the picture appeared on the center of the screen for $2000 \mathrm{~ms}$. Between each trial, another blank screen was presented during 2000 ms. Subjects were encouraged to blink in this time period. There was a break after each quarter of the experiment, which lasted approximately $35 \mathrm{~min}$ in total.

The electroencephalogram (EEG) was acquired by the continuous recording of 128 electrodes placed on a soft nylon cap with standard 10-5 locations (Oostenveld and Praamstra, 2001). Signals were recorded with the Biosemi ActiveTwo system (Biosemi V.O.F Amsterdam, Netherlands) at a $512 \mathrm{~Hz}$ sample, with filters DC to $104 \mathrm{~Hz}$ and $3 \mathrm{~dB}$ /octave slope.

\footnotetext{
${ }^{1}$ Psychology Software Tools, Inc. [E-Prime 2.0]. Retrieved from http://www.pstnet.com/
} 


\section{Data Analysis}

\section{Behavioral Analysis}

We first excluded from the behavioral data all trials in which participants did not produce the expected single target word or when no response was given within the $2 \mathrm{~s}$ time limit. For every correct trial, the reaction time (RT) corresponding to the vocal onset was defined manually according to the spectrogram and the waveform with the software Check Vocal (CheckVocal 2.2.6, Protopapas, 2007). Naming latencies situated below or above three standard deviations of each subject's mean were excluded. The statistical analyses were conducted with R software (R Development Core Team, 2003). The errors were analyzed with generalized mixed-effects models for binomial distributions (Jaeger, 2008) and the production latencies with linear mixedeffects regression models (Baayen et al., 2008).

\section{EEG Analysis}

The pre-analyses were conducted with Cartool software 3.60 (Brunet et al., 2011). Epochs of $600 \mathrm{~ms}$ time-locked to $150 \mathrm{~ms}$ before the picture onset (stimulus-locked) and epochs of $450 \mathrm{~ms}$ time-locked to $100 \mathrm{~ms}$ before the vocal onset (response-locked) were extracted and averaged for each subject across conditions, with butterworth filters set to $0.2-30 \mathrm{~Hz}$ (2nd order acausal Butterworth filter with $-12 \mathrm{~dB} /$ octave roll-off). All epochs related to correct productions were recalculated against the average reference, visually inspected and accepted only in the absence of artifact, such as eyeblinks, motor artifacts or large amplitude variations. Only trials with artifact-free stimulus- and response-locked epochs were retained. Contaminated electrodes (up to $15 \%$ of the 128 electrodes) were interpolated with a 3-D splines interpolation (Perrin et al., 1987).

The FieldTrip MATLAB software toolbox (Oostenveld et al., 2011) with custom scripts was used to analyze the waveform amplitudes over the entire data set at each time point on the 128 electrodes separately on stimulus- and responselocked ERPs. In order to identify in which time-windows significant clusters showed divergences in ERP amplitudes between the unrelated condition (UNR) and the semantically related conditions (ASS, CAT), non-parametric cluster-based permutations were computed (2000 randomizations with a spatial threshold at four clustered electrodes and alpha criterion above 0.01 for each time point). We used such a conservative threshold in order to minimize the bias of multiple comparisons. In the spatio-temporal/topographic analysis, we first tested whether conditions showed significant differences in global dissimilarity using non-parametric randomization tests (called "TANOVAs" without being an analysis of variance) with the RAGU software (Koenig et al., 2011). Data were normalized (L2 norm) and 5000 runs of randomization were computed. "TANOVAs" were calculated between the unrelated condition (UNR) and each of the semantically related conditions (ASS, CAT). Topographic differences in time-windows longer than 20 ms and with an alpha criterion below 0.01 for each time point were retained. In order to cover the entire planning process in each condition, the grand means of stimulus- and response-locked epochs were combined according to RTs by removing the overlapping signal. The duration of the combined waveforms of the grand averages corresponded to the mean naming latencies of the group of subjects in each condition and the same procedure was applied to each individual ERP. Then, the spatio-temporal clustering of stable microstate maps was conducted on the grand averages with the K-Means clustering algorithm in the Cartool software (5000 runs of randomization). This procedure segments ERPs in periods of quasi-stable global electrophysiological patterns at scalp (i.e., topographic maps or ERP microstates) by compressing the variability of ERPs in a series of template maps which summarize the data according to which topographic template best explains the group-averaged ERP responses to each experimental condition (Pascual-Marqui et al., 1995; Michel and Murray, 2012). The selection of the optimal number of ERP maps that best explain the group-averaged data across conditions was based on a combination of multiple criteria such as cross-validation and Krzanovski-Lai (see Murray et al., 2008). Statistical smoothing was applied to remove temporally isolated topographic maps with low explanatory power. Clusters that correlated above $97 \%$ were merged and segments shorter than $20 \mathrm{~ms}$ were rejected. The statistical validation of this analysis was obtained with a fitting procedure that consisted in comparing each of the microstates observed in the grand averages with the moment-by-moment scalp topography of single-subjects' ERPs. Repeated measures analysis of variance (ANOVAs) were then calculated with an alpha criterion below 0.01 to compare the mean duration and the mean global explained variance (GEV) of the fitted microstates across subjects in each condition, with Fisher LSD tests for the pairwise comparisons.

\section{RESULTS}

\section{Behavioral Results}

Of the 8496 trials, $1.94 \%$ were errors and $1.79 \%$ were situated below or above three standard deviations of each subject's mean, leading to $3.73 \%$ data loss. The errors were distributed as follows: categorical semantic (41\%), no responses (22\%), hesitations (21\%), unrelated (5\%), associative semantic (4\%), phonological (4\%) and morphological (3\%). In the error analysis, the ASS condition led to a lower rate of errors, as compared to the UNR $(z=1.923, p=0.05)$ and the CAT conditions $(z=-2.014$, $p=0.04)$, but there was no difference between UNR and CAT conditions $(z=-0.094, p=0.925)$.

The production latencies for each condition are presented in Table 2. The analyses revealed a significant effect of condition $\left(F_{(2,8083.9)}=60.323, p<0.001\right)$, number of primes $\left(F_{(1,8083.8)}=68.76, p<0.001\right)$, item repetition $\left(F_{(5,8083.9)}=50.264\right.$, $p<0.001)$ and a significant interaction between the condition and number of primes $\left(F_{(2,8083.8)}=7.676, p<0.001\right)$. We therefore conducted separate analyses for single and double priming.

In single word priming, the model indicated a significant effect of condition $\left(F_{(2,3984)}=13.831, p<0.001\right)$ and item repetition $\left(F_{(5,3984)}=20.541, p<0.001\right)$. Pairwise comparisons showed that both CAT and ASS conditions led to faster RTs as 
TABLE 2 | Mean reaction time (and standard deviation) in $\mathrm{ms}$ for each condition.

\begin{tabular}{lccc}
\hline & Associative & Categorical & Unrelated \\
\hline Single priming & $697(154)$ & $706(146)$ & $720(141)$ \\
Double priming & $662(161)$ & $688(138)$ & $709(142)$
\end{tabular}

compared to UNR condition (CAT vs. UNR : $t_{(3985)}=-3.281$, $\beta=-15.34, \mathrm{SE}=4.68, p=0.001$; ASS vs. $\mathrm{UNR}: t_{(3985)}=5.137$, $\beta=-24.02, \mathrm{SE}=4.68, p<0.001)$. Although only marginally significant $\left(t_{(3985)}=-1.857, \beta=8.68, \mathrm{SE}=4.68, p=0.06\right)$, the ASS condition also led to faster RTs as compared to the CAT condition. In double word priming, significant effects of condition $\left(F_{(2,4013)}=53.391, p<0.001\right)$ and item repetition $\left(F_{(5,4013)}=30.84, p<0.001\right)$ also appeared. A similar pattern to single priming was observed in two by two comparisons of double priming (ASS vs. CAT: $t_{(4014)}=5.887, \beta=28.17, \mathrm{SE}=4.79$, $p<0.001$; CAT vs. UNR : $t_{(4014)}=-4.193, \beta=-20.14, \mathrm{SE}=4.8$, $p<0.001$; ASS vs. UNR : $t_{(4013)}=-10.113, \beta=-48.3, \mathrm{SE}=4.78$, $p<0.001)$.

In summary, RTs decreased as follows through the conditions: UNR $>$ CAT > ASS, with a further speeding effect of the double word priming.

\section{EEG Results}

All 24 subjects were included in the subsequent analysis with $61 \%-98.3 \%$ of artifact-free epochs accepted per condition. We conducted separate analyses for single priming and double priming, due to the interaction between the condition and the number of primes.

\section{Single Word Priming}

In the waveforms' amplitudes analysis of stimulus-locked ERPs, there were significant differences from about 355 to $420 \mathrm{~ms}$ post-picture onset between the UNR and ASS conditions (Figure 1A left), and from about 330 to $430 \mathrm{~ms}$ post-picture onset between the UNR and CAT conditions (Figure 1A right). In both cases, the differences concerned large clusters of central electrodes. In this time-window, the waveforms of the related conditions (CAT and ASS) were less negative than the unrelated condition notably on the electrode $\mathrm{Cz}$ (Figure 1A). There were no significant amplitude differences between ASS and CAT conditions on stimulus-locked ERPs. No difference was observed on response-aligned ERPs whenever.

In the spatio-temporal segmentation analysis, a topographic consistency test (Koenig and Melie-García, 2010) confirmed a consistent pattern of active sources for each condition across subjects during the whole stimulus- and responselocked averaged epochs. The TANOVAs revealed topographic differences from about 335 to $450 \mathrm{~ms}$ post picture onset for the UNR-ASS comparison (Figure 1B left), and from about 340 to $435 \mathrm{~ms}$ post picture onset for the UNR-CAT comparison (Figure 1B right), closely matching the time-windows of significant differences on waveforms' amplitudes. TANOVAs between ASS and CAT conditions revealed no significant topographic difference. In response-locked ERPs, no topographic difference appeared between conditions. The spatio-temporal segmentation on the combined grand average ERPs starting
$150 \mathrm{~ms}$ pre-picture to $100 \mathrm{~ms}$ pre-response identified six different periods of quasi-stable topographic patterns summarizing the EEG signal of each condition and accounting for $98.1 \%$ of the variance of the data (Figure 1C). Following visual inspection of the time distribution of those six maps and the TANOVAs results, the fitting of these topographic patterns in the individual ERPs was conducted in two different time-windows: $0-300 \mathrm{~ms}$ (first four map templates) and $300 \mathrm{~ms}$ to the end of the signal (last two maps). The mean duration and GEV of each map per condition across participants are presented in Table 3. The GEV corresponds to the variance within these two fitting time-windows (and not within the entire planning period). Statistical comparisons on the duration of each map between conditions were significant only for map $5\left(F_{(2,46)}=6.899\right.$, $p=0.002)$. Map 5 was shorter in the ASS $(p=0.003)$ and CAT conditions $(p=0.002)$ as compared to the UNR condition. The GEV analysis showed convergent results as the GEV was modulated by the conditions only in map $5\left(F_{(2,46)}=5.268\right.$, $p=0.009)$. The GEV was higher in the ASS $(p=0.02)$ and CAT $(p=0.004)$ conditions as compared to the UNR condition.

\section{Double Word Priming}

In the waveforms' amplitudes analysis, the UNR-ASS comparison showed significant differences in three timewindows: from $-145 \mathrm{~ms}$ to $-70 \mathrm{~ms}$ pre-picture, from $-30 \mathrm{~ms}$ pre-picture to $35 \mathrm{~ms}$ post-picture onset and from $285 \mathrm{~ms}$ to $445 \mathrm{~ms}$ post-picture onset (Figure $2 \mathrm{~A} \mathrm{left}$ ). In the first and second time-windows, the differences involved large clusters of anterior and posterior electrodes, whereas in the third timewindow, they were on central electrodes. In the UNR-CAT comparison, two time-windows of significant amplitude differences emerged: $275-320$ and $375-405$ ms post-picture onset (Figure 2A right), involving clusters of anterior and central electrodes. The waveforms of the related conditions were less negative than the unrelated condition (Figure 2A). The ASS-CAT comparison of stimulus-locked ERPs showed significant amplitude differences from $-35 \mathrm{~ms}$ pre-picture to $25 \mathrm{~ms}$ post-picture onset. There were no significant amplitude differences in the response-locked ERPs.

In the spatio-temporal segmentation analysis, a topographic consistency test (Koenig and Melie-García, 2010) also confirmed a consistent pattern of active sources for each condition across subjects during the whole stimulus- and response-locked averaged epochs. The UNR-ASS comparison revealed significant topographic differences -140 to $-60 \mathrm{~ms}$ pre-picture, $-30 \mathrm{~ms}$ pre-picture to $85 \mathrm{~ms}$ post picture onset and from 310 to $450 \mathrm{~ms}$ post picture onset (Figure 2B). The UNR-CAT comparison showed topographic differences -140 to $-115 \mathrm{~ms}$ pre-picture and from $360 \mathrm{~ms}$ to $430 \mathrm{~ms}$ post-picture onset (Figure 2B). As for the ASS-CAT comparison, it revealed topographic differences in two time-windows, namely $-35 \mathrm{~ms}$ pre-picture to $35 \mathrm{~ms}$ post-picture onset and $55-80 \mathrm{~ms}$ post-picture onset, overlapping waveform amplitudes differences (not illustrated). In responselocked ERPs, no significant topographic difference appeared between the conditions.

The spatio-temporal segmentation on the combined ERP grand averages and the fitting in the individual ERPs was 


\section{A}
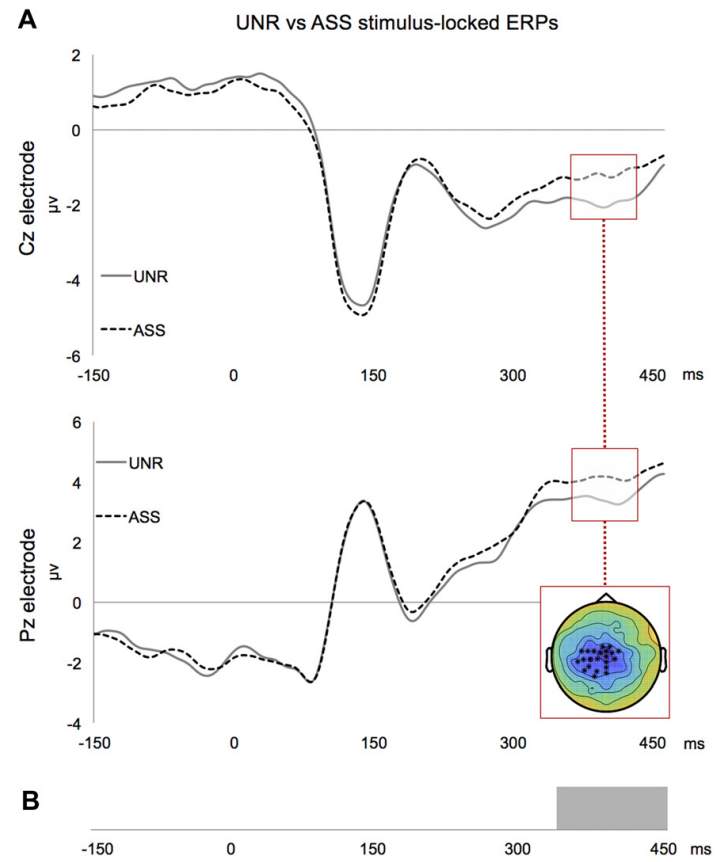

C

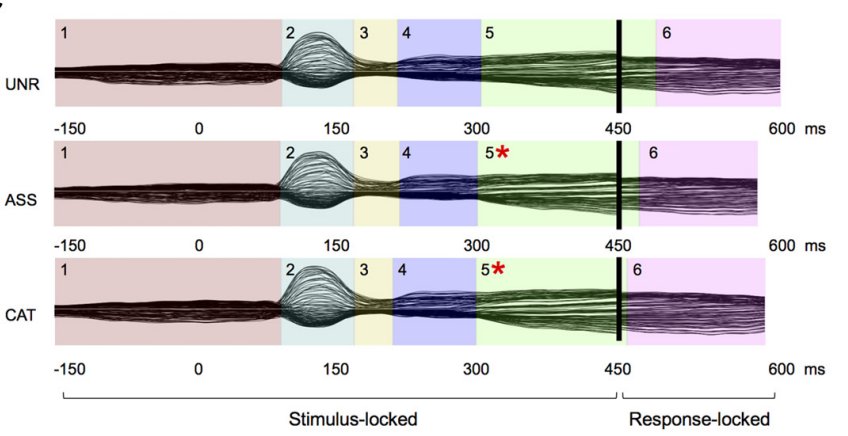

UNR vs CAT stimulus-locked ERPs

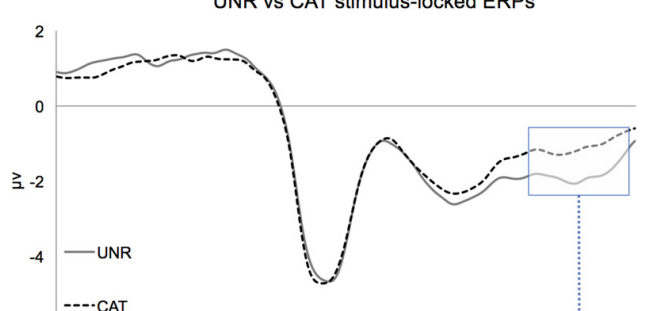

$-\left.6\right|_{-150} ^{-\cdots \cdot C A T} \quad 0$

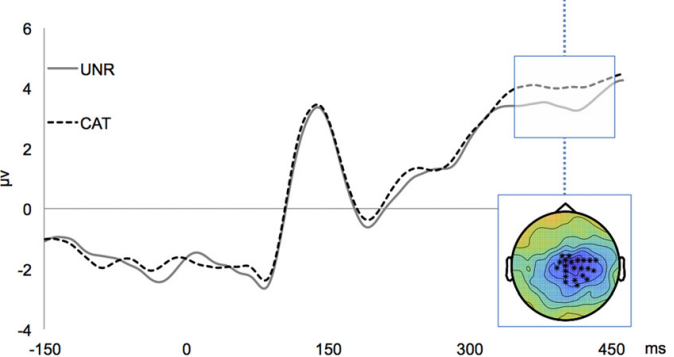

150

$450 \mathrm{~ms}$

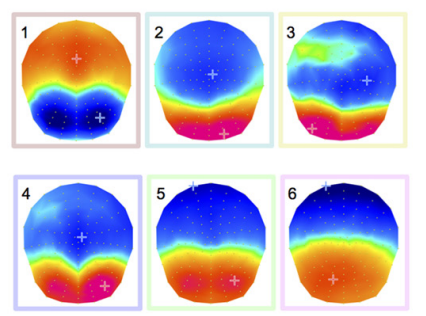

$50 \mathrm{~ms}$

FIGURE 1 | Results for single word priming. (A) Examples of group-averaged waveforms for the UNR-ASS (left) and UNR-CAT (right) contrasts on stimulus-locked ERPS: time-windows of significant clusters over at least four electrodes are highlighted and all electrodes showing the highlighted effect are crossed on the topographical representation. (B) Results of "TANOVA" spatio-temporal analysis for the same contrasts: bars represent time-periods of significant differences in global similarity. (C) Temporal distribution of stable electrophysiological patterns at scalp from the spatio-temporal segmentation on the combined stimulus- and response-locked grand averages matching the actual reaction times of each experimental condition (*indicates a significant difference in map duration).

conducted in the same way as for single priming (Figure 2C). Again, six different microstates were found, accounting for $97.9 \%$ of the variance of the data (Figure 1C). Given the similar distribution of maps, the same fitting periods as for single word priming were used. When comparing the duration of each map per condition (Table 4), significant differences were found on map $1\left(F_{(2,46)}=5.305, p=0.008\right)$ and map $5\left(F_{(2,46)}=10.831\right.$, $p<0.001)$. More precisely, map 1 was shorter in the ASS condition as compared to the two other conditions (ASS vs. UNR: $p=0.002$; ASS vs. CAT: $p=0.05$ ), without duration

TABLE 3 | Mean duration (in ms) and Global Explained Variance (GEV, in \%) of the six microstates in each condition for single word priming according to the fitting procedure in the individual ERPs.

\begin{tabular}{|c|c|c|c|c|c|c|c|}
\hline & & \multicolumn{4}{|c|}{ Fitting from $150 \mathrm{~ms}$ before picture to $300 \mathrm{~ms}$} & \multicolumn{2}{|c|}{ Fitting from $300 \mathrm{~ms}$ to $100 \mathrm{~ms}$ before RT } \\
\hline & & Map 1 & Map 2 & Map 3 & Map 4 & Map 5 & Map 6 \\
\hline \multirow[t]{2}{*}{ UNR } & Duration (ms) & 249 & 117 & 26 & 58 & 166 & 154 \\
\hline & GEV (\%) & $9.5 \%$ & $5.9 \%$ & $1.0 \%$ & $2.3 \%$ & $13.7 \%$ & $12.0 \%$ \\
\hline \multirow[t]{2}{*}{ ASS } & Duration (ms) & 243 & 110 & 35 & 64 & 132 & 164 \\
\hline & GEV (\%) & $9.2 \%$ & $5.8 \%$ & $1.1 \%$ & $2.8 \%$ & $11.5 \%$ & $12.5 \%$ \\
\hline \multirow[t]{2}{*}{ CAT } & Duration (ms) & 244 & 128 & 27 & 52 & 130 & 173 \\
\hline & GEV (\%) & $9.5 \%$ & $6.3 \%$ & $0.9 \%$ & $2.3 \%$ & $10.9 \%$ & $14.0 \%$ \\
\hline
\end{tabular}


A

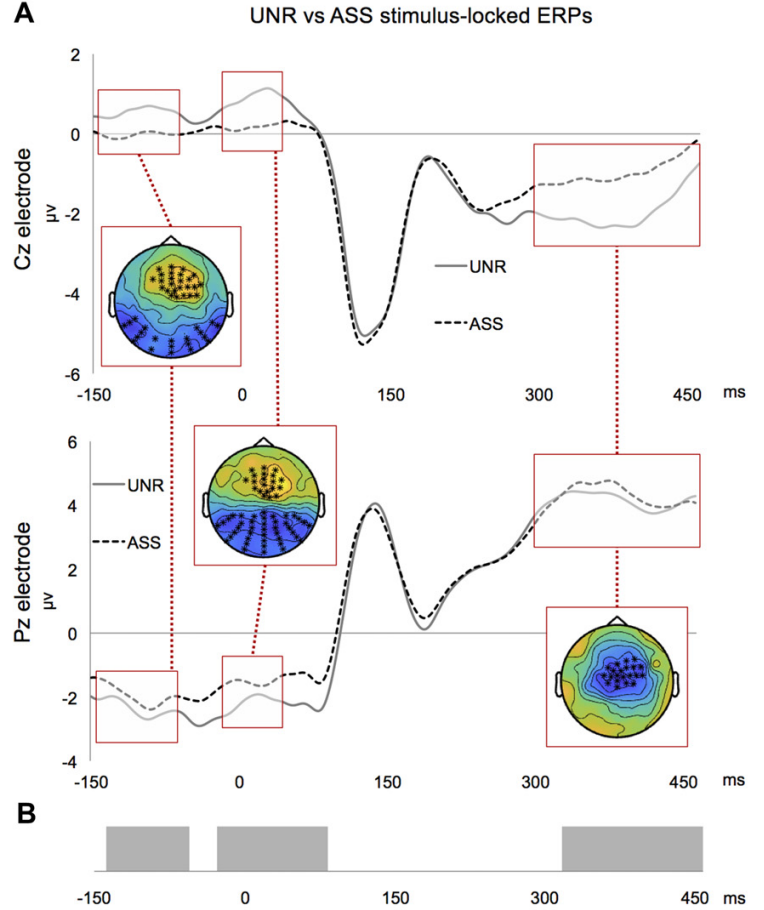

UNR vs CAT stimulus-locked ERPs

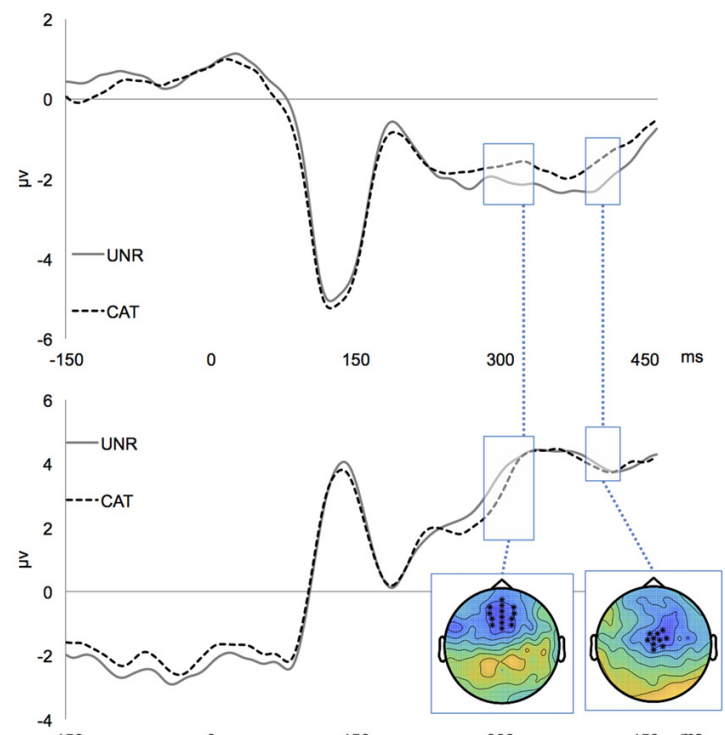

150

300

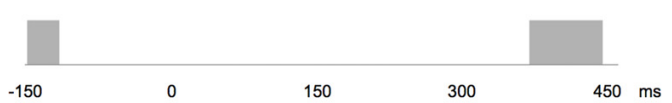

C
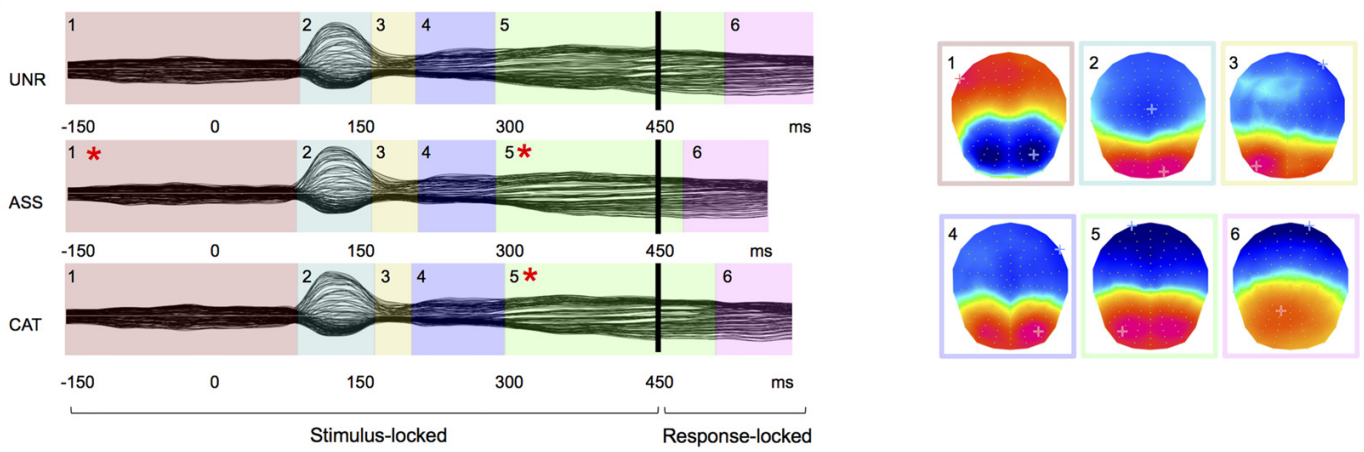

FIGURE 2 | Results for double word priming. (A) Examples of group-averaged waveforms for the UNR-ASS (left) and UNR-CAT (right) contrasts on stimulus-locked ERPs: time-windows of significant clusters over at least four electrodes are highlighted and all electrodes showing the highlighted effect are crossed on the topographical representations. (B) Results of "TANOVA" spatio-temporal analysis for the same contrasts: bars represent time-periods of significant differences in global similarity. (C) Temporal distribution of stable electrophysiological patterns at scalp from the spatio-temporal segmentation on the combined stimulus- and response-locked grand averages matching the actual reaction times of each experimental condition (*indicates a significant difference in map duration).

difference between UNR and CAT $(p=0.25)$. As for map 5, it was significantly shorter in semantic-high conditions as compared to the semantic-low condition (UNR vs. ASS: $p<0.001$; UNR vs. CAT: $p=0.008$ ), without significant difference between ASS and CAT $(p=0.07)$. For both maps, convergent results were found on the GEV, which varied significantly across conditions for map 1 $\left(F_{(2,46)}=13.538, p<0.001\right)$ and map $5\left(F_{(2,46)}=10.603\right)$. On map 1, the GEV was lower in the ASS condition as compared to the UNR $(p<0.001)$ and CAT $(p<0.001)$ conditions, with no difference between UNR and CAT $(p=0.24)$. On map 5, the GEV in the semantic-high conditions was lower than in the UNR condition (UNR vs. ASS: $p<0.001$; UNR vs. CAT: $p=0.006)$, but no difference appeared between ASS and $\operatorname{CAT}(p=0.09)$.

\section{DISCUSSION}

Using a PWIP with a rather long negative SOA, we observed that picture naming was speeded up with associative and categorical primes, as compared to unrelated primes. A lengthened SOA was sufficient to overcome the interfering effect that was observed in the preliminary experiment at a SOA of $-66 \mathrm{~ms}$. Interestingly, associative primes accelerated the speech planning process more than categorical primes did. This is in line with previous reports showing that thematic/associative relations induce less lexical competition than categorical ones (e.g., Costa et al., 2005). When the prime and the target belong to the same category (e.g., penguin-eagle), they also share several semantic features, leading to the activation of multiple concepts 
TABLE 4 | Mean duration (in ms) and Global Explained Variance (GEV, in \%) of the six microstates in each condition for double word priming according to the fitting procedure in the individual ERPs.

\begin{tabular}{|c|c|c|c|c|c|c|c|}
\hline & & \multicolumn{4}{|c|}{ Fitting from $150 \mathrm{~ms}$ before picture to $300 \mathrm{~ms}$} & \multicolumn{2}{|c|}{ Fitting from $300 \mathrm{~ms}$ to $100 \mathrm{~ms}$ before RT } \\
\hline & & Map 1 & Map 2 & Map 3 & Map 4 & Map 5 & Map 6 \\
\hline \multirow[t]{2}{*}{ UNR } & Duration (ms) & 246 & 90 & 30 & 86 & 194 & 114 \\
\hline & GEV (\%) & $10.6 \%$ & $4.7 \%$ & $1.1 \%$ & $4.2 \%$ & $18.3 \%$ & $9.7 \%$ \\
\hline \multirow[t]{2}{*}{ ASS } & Duration (ms) & 212 & 122 & 32 & 85 & 134 & 131 \\
\hline & GEV (\%) & $8.3 \%$ & $5.7 \%$ & $1.1 \%$ & $4.2 \%$ & $12.4 \%$ & $10.7 \%$ \\
\hline \multirow[t]{2}{*}{ CAT } & Duration (ms) & 233 & 104 & 33 & 81 & 158 & 128 \\
\hline & GEV (\%) & $10.0 \%$ & $5.2 \%$ & $1.0 \%$ & $3.9 \%$ & $14.6 \%$ & $10.8 \%$ \\
\hline
\end{tabular}

spreading to multiple lexical entries competing for selection. But when the prime and the target are associated (e.g., penguinice), less semantic features are shared and lexical competition is weaker (Abdel Rahman and Melinger, 2009) or absent (de Zubicaray et al., 2014), as compared to the categorical condition. In addition, picture naming was also faster with a double priming as compared to a single priming in the ASS and CAT conditions. In the same way as in semantic interference (Abdel Rahman and Melinger, 2008), we provide here the first observation that multiple primes can increase semantic facilitation effects. However, contrary to interference effects, the present result can hardly be explained by increased lexical competition. In the next sections, we will discuss the time-windows of the semantic facilitation effects and how they contribute to the understanding of the processes underlying speech production.

\section{Time-Windows of Semantic Facilitation}

When comparing semantic-high conditions (ASS, CAT) with the semantic-low condition (UNR), ERP analyses showed consistent amplitude modulations in relatively late time-windows in stimulus-locked ERPs, i.e., beyond $330 \mathrm{~ms}$ post picture onset in single priming and beyond $275 \mathrm{~ms}$ in double priming, with larger amplitudes for ASS and CAT relative to UNR. Despite a $50 \mathrm{~ms}$ shift in the onset of ERP effects between single and double priming, both fall beyond the P2/N2 component which has been previously associated with the onset of lexical selection. This shift might therefore only reflect the overall speed difference (mean RT for single priming: $708 \mathrm{~ms}$ and for double priming: $686 \mathrm{~ms}$ ). This late locus is confirmed by the spatio-temporal segmentation analyses: duration differences appeared systematically on the microstate starting around $300 \mathrm{~ms}$ post picture onset (map 5 in Figures 1C, 2C), which was shorter in semantic-high conditions. Therefore, the observed ERP results likely correspond to shorter duration of similar mental processes for the primed conditions in a time-window falling after lexical selection.

In double priming, ERP amplitude modulations between the UNR and ASS conditions began already in the blank interval between the words and the picture, with larger amplitudes for UNR relative to ASS. These results converge with those from the ERP spatio-temporal analyses, in which the first microstate (map 1 in Figure 2C) is shorter in the ASS condition than in the other conditions. The pre-picture ERP effects could be due to an integration of the link between the two associative primes leading to lexical preactivation/anticipation (Dikker and Pylkkänen, 2013). Interestingly, no early/pre-picture amplitude modulation was found when comparing UNR and CAT conditions, whereas
ASS vs. CAT divergences also showed up around the picture onset. Indeed, with two ASS primes (e.g., flight, sky), the target (e.g., airplane) that underwent familiarization was quite predictable, whereas after two CAT primes (e.g., helicopter, bus), only the semantic category could be anticipated and the target remained less predictable. Some subjects could have tried to apply a strategy, i.e., guessing or anticipating each naming response during or quickly after the presentation of the associative primes. Even if this could partly account for the observed facilitation, we do not believe that our results are only due to pure guessing for the following reasons. First, semantic facilitation has been reported even with short negative SOAs (Alario et al., 2000; Damian and Abdel Rahman, 2003; Finkbeiner and Caramazza, 2006; Bölte et al., 2013; Damian and Spalek, 2014) and is not proportional to the negative SOA duration (i.e., the amount of facilitation is the same at $-1000 \mathrm{~ms}$ and -400 ms SOAs; Zhang et al., 2016). Second, clearly anticipated responses (and their corresponding ERPs) were likely eliminated by cleaning the reaction times with a cut-off set at three standard deviations for each subject's mean. Third, the late ERP effects of condition after two associative primes were distributed on a similar cluster of central electrodes than after one associative prime (Figures 1A, 2A).

As the longer negative SOA in double priming vs. single priming might just as well explain the greater facilitation that we reported here, we cannot draw conclusions about the nature of the cumulative effect of multiple primes. It could be due to strategic anticipation (i.e., the subjects know that after having seen two words the picture will appear, whereas after the first word, it can be another word or the picture) and/or from the integration of both words in relation to the target picture/concept to name. Note that after two categorical primes, the amplitude differences concern first a cluster of anterior electrodes and then central electrodes, which could also be-to some extent-indicative of partial anticipation in presence of two primes. Therefore, we will not extrapolate in comparing directly single to double priming, but rather focus on the effect of the types of primes.

\section{Underlying Processes of Semantic Facilitation}

ERP results across semantic relatedness (ASS/CAT) showed effects in the same relatively late time-window (P3/N3 components), on the same clusters of central electrodes and on same periods of stable electrophysiological pattern at 
scalp. This convergence of ERP effects might suggest that in the PWIP, at least with a long negative SOA, different semantic relationships between the prime and the target (e.g., coordinate vs. associate) can both facilitate speech production in similar ways. Moreover, it seems that the two types of primes exerted an influence on the same speech planning process in the present experiment.

Crucially, the time-window modulated by the semantic manipulation in our experiment fell beyond the P2/N2 component, which has been related to the onset of lexical selection (Maess et al., 2002; Costa et al., 2009; Strijkers et al., 2010; Aristei et al., 2011). Such late effects of semantic primes in the PWIP have been previously reported by other ERP studies (Dell'Acqua et al., 2010; Blackford et al., 2012; Shitova et al., 2016), although these studies used only coordinates and observed behavioral interference. Shitova et al. (2016) situated the effect at the word-planning stage, and the two other studies (Dell'Acqua et al., 2010; Blackford et al., 2012) provided slightly more specific interpretations and related this late effect to the activation of the phonological word-form of the picture's name. Indeed, post-lexical processes are very likely engaged after 275 ms: this time-window has been associated in previous ERP studies to phonological processes (Vihla et al., 2006), impaired phonological encoding (Laganaro et al., 2009, 2011) and differed between phonological and orthographical word form encoding in picture naming (Perret and Laganaro, 2012). Critically, "post-lexical" does not necessarily mean phonological or phonetic. It has also been shown that other variables like word age of acquisition, name agreement and image agreement modulate ERPs in late time-windows associated with post-lexical processes (Valente et al., 2014), which is in line with monitoring going on in parallel to word form encoding.

This leaves us with two possible accounts for post-lexical effects: modulations at the word-form level or/and monitoring effects. The self-monitoring internal loop, engaged as soon as the first segment of the phonological word is encoded (Indefrey and Levelt, 2004), might have been more efficient in the semantic-high conditions than in the unrelated condition. Semantic primes could have lowered the resources needed by the monitoring for the phonological preparation. Such a predominant role of self-monitoring in the PWIP is supported by the study of Dhooge and Hartsuiker (2012). According to these authors, only the implication of verbal self-monitoring can account for the polarity reversal of the effects observed in the PWIP. Interestingly, the PWIP study of Dell'Acqua et al. (2010) showed concomitant ERP effects for opposite behavioral effects (phonological facilitation and semantic interference) around $320 \mathrm{~ms}$ post picture onset, thus both compatible with the self-monitoring interpretation.

Finally, strategic processes presumably arising post-lexically might also partly explain the present "late" ERP effects: it is possible that participants adopted anticipatory strategies induced by the long negative SOA to predict some naming responses in semantic-high conditions (Alario, 2001). Even if anticipating a response by means of predictions seems very natural in everyday dialogs (Corps et al., 2018) and in sentence completion (Piai et al., 2014b), we cannot affirm straightforwardly that such anticipatory strategies have influenced the (post-lexical) time-course of speech planning and/or the self-monitoring in the present experiments. In language comprehension, prediction and anticipation already drawed the attention of psycholinguists (e.g., Brothers et al., 2015; Luke and Christianson, 2016), but in language production strategic aspects remain under-investigated until now and the level at which predictions are specified is still debated (Drake and Corley, 2015).

In sum, this article demonstrates that semantic facilitation is as suitable as semantic interference to inform on the word production process. It provides the first empirical evidence that categorical and associative facilitation share the same locus, at least in the context of the PWIP with a relatively long negative SOA. It also reports the first observation that multiple primes can increase semantic facilitation. The present data suggest that semantic facilitation effects induced by both ASS and CAT primes arise at post-lexical processing stages, without discarding the involvement of strategic processes. This interpretation is in line with Starreveld and La Heij (2017) recently warranting that Stroop and PWIP both have a "late" locus. By postlexical, we refer either to phonological processes interacting with (pre-)lexical processes (e.g., semantic integration of the prime with the target during phonological encoding), or to the implication of the verbal self-monitoring. These inferences do not seem to be restricted to the PWIP, as we recently identified ERP facilitation effects also occurring after the P2 component in the first cycle of the blocked cyclic naming paradigm (Python et al., 2018). If we stick to actual estimates for picture naming $\mathrm{RT}$ in the $600 \mathrm{~ms}$ range (Indefrey, 2011), all effects observed after $275 \mathrm{~ms}$ post picture onset are presumably post-lexical. Nonetheless, with mean naming latencies of $700 \mathrm{~ms} \pm 150 \mathrm{~ms}$, the debate remains open about the adequate way of rescaling the actual estimates to various naming latencies (Laganaro, 2016; Roelofs and Shitova, 2017). Future research is needed to better take into account the RT variability in the ERP analysis and identify not only serial stages of speech planing but consider the processes in an interactive way.

\section{DATA AVAILABILITY STATEMENT}

The list of stimuli is included in the supplementary file.

\section{AUTHOR CONTRIBUTIONS}

GP and ML: study conception and design. GP and RF: acquisition of data. GP, RF and ML: analysis and interpretation of data. GP: drafting of manuscript. RF and ML: critical revision.

\section{FUNDING}

This research was supported by Swiss National Science Foundation Grant No. 105319_146113.

\section{SUPPLEMENTARY MATERIAL}

The Supplementary Material for this article can be found online at: https://www.frontiersin.org/articles/10.3389/fnhum. 2018.00136/full\#supplementary-material 


\section{REFERENCES}

Abdel Rahman, R., and Melinger, A. (2008). Enhanced phonological facilitation and traces of concurrent word form activation in speech production: an objectnaming study with multiple distractors. Q. J. Exp. Psychol. 61, 1410-1440. doi: 10.1080/17470210701560724

Abdel Rahman, R., and Melinger, A. (2009). Semantic context effects in language production: a swinging lexical network proposal and a review. Lang. Cogn. Process. 24, 713-734. doi: 10.1080/01690960802597250

Alario, F.-X. (2001). Aspects sémantiques de l'accès au lexique au cours de la production de parole [Semantic aspects of lexical access during word production]. Psychol. Fr. 46, 17-26. Available online at: http://www.refdoc.fr/Detailnotice?cpsidt=910611

Alario, F.-X., and Ferrand, L. (1999). A set of 400 pictures standardized for French: norms for name agreement, image agreement, familiarity, visual complexity, image variability, and age of acquisition. Behav. Res. Methods Instrum. Comput. 31, 531-552. doi: 10.3758/bf03200732

Alario, F.-X., Segui, J., and Ferrand, L. (2000). Semantic and associative priming in picture naming. Q. J. Exp. Psychol. A 53, 741-764. doi: 10.1080/ 027249800410535

Aristei, S., Melinger, A., and Abdel Rahman, R. (2011). Electrophysiological chronometry of semantic context effects in language production. J. Cogn. Neurosci. 23, 1567-1586. doi: 10.1162/jocn.2010.21474

Baayen, R. H., Davidson, D. J., and Bates, D. M. (2008). Mixed-effects modeling with crossed random effects for subjects and items. J. Mem. Lang. 59, 390-412. doi: 10.1016/j.jml.2007.12.005

Blackford, T., Holcomb, P. J., Grainger, J., and Kuperberg, G. R. (2012). A funny thing happened on the way to articulation: N400 attenuation despite behavioral interference in picture naming. Cognition 123, 84-99. doi: 10.1016/j.cognition. 2011.12.007

Bloem, I., van den Boogaard, S., and La Heij, W. (2004). Semantic facilitation and semantic interference in language production: further evidence for the conceptual selection model of lexical access. J. Mem. Lang. 51, 307-323. doi: 10.1016/j.jml.2004.05.001

Bölte, J., Dohmes, P., and Zwitserlood, P. (2013). Interference and facilitation in spoken word production: effects of morphologically and semantically related context stimuli on picture naming. J. Psycholinguist. Res. 42, 255-280. doi: 10.1007/s10936-012-9219-1

Bonin, P., Peereman, R., Malardier, N., Méot, A., and Chalard, M. (2003). A new set of 299 pictures for psycholinguistic studies: french norms for name agreement, image agreement, conceptual familiarity, visual complexity, image variability, age of acquisition, and naming latencies. Behav. Res. Methods Instrum. Comput. 35, 158-167. doi: 10.3758/bf03195507

Brothers, T., Swaab, T. Y., and Traxler, M. J. (2015). Effects of prediction and contextual support on lexical processing: prediction takes precedence. Cognition 136, 135-149. doi: 10.1016/j.cognition.2014.10.017

Brunet, D., Murray, M. M., and Michel, C. M. (2011). Spatiotemporal analysis of multichannel EEG: CARTOOL. Comput. Intell. Neurosci. 2011:813870. doi: $10.1155 / 2011 / 813870$

Bueno, S., and Megherbi, H. (2009). French categorization norms for 70 semantic categories and comparison with Van Overschelde et al.'s (2004) English norms. Behav. Res. Methods 41, 1018-1028. doi: 10.3758/BRM.41.4.1018

Chen, Q., and Mirman, D. (2012). Competition and cooperation among similar representations: toward a unified account of facilitative and inhibitory effects of lexical neighbors. Psychol. Rev. 119, 417-430. doi: 10.1037/a0027175

Collina, S., Tabossi, P., and De Simone, F. (2013). Word production and the picture-word interference paradigm: the role of learning. J. Psycholinguist. Res. 42, 461-473. doi: 10.1007/s10936-012-9229-z

Collins, A. M., and Loftus, E. F. (1975). A spreading-activation theory of semantic processing. Psychol. Rev. 82, 407-428. doi: 10.1037/0033-295x. 82.6.407

Corps, R. E., Gambi, C., and Pickering, M. J. (2018). Coordinating utterances during turn-taking: the role of prediction, response preparation, and articulation. Discourse Process. 55, 230-240. doi: 10.1080/0163853x.2017. 1330031

Costa, A., Alario, F. X., and Caramazza, A. (2005). On the categorical nature of the semantic interference effect in the picture-word interference paradigm. Psychon. Bull. Rev. 12, 125-131. doi: 10.3758/bf03196357
Costa, A., Mahon, B., Savova, V., and Caramazza, A. (2003). Level of categorisation effect: a novel effect in the picture-word interference paradigm. Lang. Cogn. Process. 18, 205-234. doi: 10.1080/01690960143000524

Costa, A., Strijkers, K., Martin, C., and Thierry, G. (2009). The time course of word retrieval revealed by event-related brain potentials during overt speech. Proc. Natl. Acad. Sci. U S A 106, 21442-21446. doi: 10.1073/pnas.0908 921106

Damian, M. F., and Abdel Rahman, R. (2003). Semantic priming in the name retrieval of objects and famous faces. Br. J. Psychol. 94, 517-527. doi: 10.1348/000712603322503079

Damian, M. F., and Bowers, J. S. (2003). Locus of semantic interference in picture-word interference tasks. Psychon. Bull. Rev. 10, 111-117. doi: 10.3758/bf03196474

Damian, M. F., and Spalek, K. (2014). Processing different kinds of semantic relations in picture-word interference with non-masked and masked distractors. Front. Psychol. 5:1183. doi: 10.3389/fpsyg.2014.01183

de Zubicaray, G. I., Hansen, S., and McMahon, K. L. (2013). Differential processing of thematic and categorical conceptual relations in spoken word production. J. Exp. Psychol. Gen. 142, 131-142. doi: 10.1037/a0028717

de Zubicaray, G., Johnson, K., Howard, D., and McMahon, K. (2014). A perfusion fMRI investigation of thematic and categorical context effects in the spoken production of object names. Cortex 54, 135-149. doi: 10.1016/j.cortex.2014. 01.018

Dell, G. S., and O’Seaghdha, P. G. (1991). Mediated and convergent lexical priming in language production: a comment on Levelt et al. (1991). Psychol. Rev. 98, 604-614; discussion 615-618. doi: 10.1037/0033-295x.98.4.604

Dell'Acqua, R., Sessa, P., Peressotti, F., Mulatti, C., Navarrete, E., and Grainger, J. (2010). ERP evidence for ultra-fast semantic processing in the picture-word interference paradigm. Front. Psychol. 1:177. doi: 10.3389/fpsyg.2010. 00177

Dhooge, E., and Hartsuiker, R. J. (2012). Lexical selection and verbal self-monitoring: effects of lexicality, context, and time pressure in picture-word interference. J. Mem. Lang. 66, 163-176. doi: 10.1016/j.jml.2011. 08.004

Dikker, S., and Pylkkänen, L. (2013). Predicting language: MEG evidence for lexical preactivation. Brain Lang. 127, 55-64. doi: 10.1016/j.bandl.2012. 08.004

Drake, E., and Corley, M. (2015). Effects in production of word pre-activation during listening: are listener-generated predictions specified at a speech-sound level? Mem. Cognit. 43, 111-120. doi: 10.3758/s13421-014-0451-9

Ferrand, L., and Alario, F.-X. (1998). Normes d'associations verbales pour 366 noms d’objets concrets. Année Psychol. 98, 659-709. doi: 10.3406/psy.1998. 28564

Finkbeiner, M., and Caramazza, A. (2006). Now you see it, now you don't: on turning semantic interference into facilitation in a Stroop-like task. Cortex 42 , 790-796. doi: 10.1016/s0010-9452(08)70419-2

Francis, W. S. (2014). Repetition priming in picture naming: sustained learning through the speeding of multiple processes. Psychon. Bull. Rev. 21, 1301-1308. doi: 10.3758/s13423-014-0610-9

Ganushchak, L. Y., and Schiller, N. O. (2008). Motivation and semantic context affect brain error-monitoring activity: an event-related brain potentials study. Neuroimage 39, 395-405. doi: 10.1016/j.neuroimage.2007.09.001

Glaser, W. R., and Düngelhoff, F. J. (1984). The time course of picture-word interference. J. Exp. Psychol. Hum. Percept. Perform. 10, 640-654. doi: 10.1037/0096-1523.10.5.640

Griffin, Z. M., and Bock, K. (1998). Constraint, word frequency, and the relationship between lexical processing levels in spoken word production. J. Mem. Lang. 38, 313-338. doi: 10.1006/jmla.1997.2547

Hantsch, A., Jescheniak, J. D., and Mädebach, A. (2012). Naming and categorizing objects: task differences modulate the polarity of semantic effects in the picture-word interference paradigm. Mem. Cognit. 40, 760-768. doi: 10.3758/s13421-012-0184-6

Hantsch, A., Jescheniak, J. D., and Schriefers, H. (2005). Semantic competition between hierarchically related words during speech planning. Mem. Cognit. 33, 984-1000. doi: 10.3758/bf03193207

Hantsch, A., Jescheniak, J. D., and Schriefers, H. (2009). Distractor modality can turn semantic interference into semantic facilitation in the picture-word interference task: implications for theories of lexical access 
in speech production. J. Exp. Psychol. Learn. Mem. Cogn. 35, 1443-1453. doi: $10.1037 / \mathrm{a} 0017020$

Hirschfeld, G., Jansma, B., Bölte, J., and Zwitserlood, P. (2008). Interference and facilitation in overt speech production investigated with eventrelated potentials. Neuroreport 19, 1227-1230. doi: 10.1097/WNR.0b013e3283 09 ecdl 1

Howard, D., Nickels, L., Coltheart, M., and Cole-Virtue, J. (2006). Cumulative semantic inhibition in picture naming: experimental and computational studies. Cognition 100, 464-482. doi: 10.1016/j.cognition.2005.02.006

Hutson, J., and Damian, M. F. (2014). Semantic gradients in picture-word interference tasks: is the size of interference effects affected by the degree of semantic overlap? Front. Psychol. 5:872. doi: 10.3389/fpsyg.2014.00872

Indefrey, P. (2011). The spatial and temporal signatures of word production components: a critical update. Front. Psychol. 2:255. doi: 10.3389/fpsyg.2011. 00255

Indefrey, P., and Levelt, W. J. M. (2004). The spatial and temporal signatures of word production components. Cognition 92, 101-144. doi: 10.1016/j.cognition. 2002.06.001

Jaeger, T. F. (2008). Categorical data analysis: away from ANOVAs (transformation or not) and towards logit mixed models. J. Mem. Lang. 59, 434-446. doi: 10.1016/.j.jml.2007.11.007

Janssen, N., Schirm, W., Mahon, B. Z., and Caramazza, A. (2008). Semantic interference in a delayed naming task: evidence for the response exclusion hypothesis. J. Exp. Psychol. Learn. Mem. Cogn. 34, 249-256. doi: 10.1037/02787393.34.1.249

Koenig, T., Kottlow, M., Stein, M., and Melie-García, L. (2011). Ragu: a free tool for the analysis of EEG and MEG event-related scalp field data using global randomization statistics. Comput. Intell. Neurosci. 2011:938925. doi: 10.1155/2011/938925

Koenig, T., and Melie-García, L. (2010). A method to determine the presence of averaged event-related fields using randomization tests. Brain Topogr. 23, 233-242. doi: 10.1007/s10548-010-0142-1

Kuipers, J.-R., and La Heij, W. (2008). Semantic facilitation in category and action naming: testing the message-congruency account. J. Mem. Lang. 58, 123-139. doi: 10.1016/j.jml.2007.05.005

Kuipers, J.-R., La Heij, W., and Costa, A. (2006). A further look at semantic context effects in language production: the role of response congruency. Lang. Cogn. Process. 21, 892-919. doi: 10.1080/016909600824211

La Heij, W. (1988). Components of Stroop-like interference in picture naming. Mem. Cognit. 16, 400-410. doi: 10.3758/bf03214220

La Heij, W., and van den Hof, E. (1995). Picture-word interference increases with target-set size. Psychol. Res. 58, 119-133. doi: 10.1007/bf00571100

Laganaro, M. (2016). Dynamics of word production and processing speed. Lang. Cogn. Neurosci. 31, 463-464. doi: 10.1080/23273798.2015.1096402

Laganaro, M., Morand, S., Michel, C. M., Spinelli, L., and Schnider, A. (2011). ERP correlates of word production before and after stroke in an aphasic patient. J. Cogn. Neurosci. 23, 374-381. doi: 10.1162/jocn.2010.21412

Laganaro, M., Morand, S., Schwitter, V., Zimmermann, C., Camen, C., and Schnider, A. (2009). Electrophysiological correlates of different anomic patterns in comparison with normal word production. Cortex 45, 697-707. doi: 10.1016/j.cortex.2008.09.007

Levelt, W. J., Roelofs, A., and Meyer, A. S. (1999). A theory of lexical access in speech production. Behav. Brain Sci. 22, 1-38; discussion 38-75. doi: $10.1017 /$ S0140525X99001776

Lucas, M. (2000). Semantic priming without association: a meta-analytic review. Psychon. Bull. Rev. 7, 618-630. doi: 10.3758/bf03212999

Luke, S. G., and Christianson, K. (2016). Limits on lexical prediction during reading. Cogn. Psychol. 88, 22-60. doi: 10.1016/j.cogpsych.2016.06.002

Lupker, S. J. (1979). The semantic nature of response competition in the picture-word interference task. Mem. Cognit. 7, 485-495. doi: $10.3758 / \mathrm{bf} 03198265$

MacLeod, C. M. (1991). Half a century of research on the Stroop effect: an integrative review. Psychol. Bull. 109, 163-203. doi: 10.1037/0033-2909. 109.2.163

Maess, B., Friederici, A. D., Damian, M. F., Meyer, A. S., and Levelt, W. J. M. (2002). Semantic category interference in overt picture naming: sharpening current density localization by PCA. J. Cogn. Neurosci. 14, 455-462. doi: $10.1162 / 089892902317361967$
Mahon, B. Z., Costa, A., Peterson, R., Vargas, K. A., and Caramazza, A. (2007). Lexical selection is not by competition: a reinterpretation of semantic interference and facilitation effects in the picture-word interference paradigm. J. Exp. Psychol. Learn. Mem. Cogn. 33, 503-535. doi: 10.1037/0278-7393.33. 3.503

Melinger, A., and Abdel Rahman, R. (2013). Lexical selection is competitive: evidence from indirectly activated semantic associates during picture naming. J. Exp. Psychol. Learn. Mem. Cogn. 39, 348-364. doi: 10.1037/a0 028941

Michel, C. M., and Murray, M. M. (2012). Towards the utilization of EEG as a brain imaging tool. Neuroimage 61, 371-385. doi: 10.1016/j.neuroimage.2011. 12.039

Murray, M. M., Brunet, D., and Michel, C. M. (2008). Topographic ERP analyses: a step-by-step tutorial review. Brain Topogr. 20, 249-264. doi: 10.1007/s10548008-0054-5

Navarrete, E., Del Prato, P., Peressotti, F., and Mahon, B. Z. (2014). Lexical selection is not by competition: evidence from the blocked naming paradigm. J. Mem. Lang. 76, 253-272. doi: 10.1016/j.jml.2014.05.003

New, B., Pallier, C., Brysbaert, M., and Ferrand, L. (2004). Lexique 2: a new French lexical database. Behav. Res. Methods Instrum. Comput. 36, 516-524. doi: 10.3758/BF03195598

Oostenveld, R., Fries, P., Maris, E., and Schoffelen, J.-M. (2011). FieldTrip: open source software for advanced analysis of MEG, EEG, and invasive electrophysiological data. Comput. Intell. Neurosci. 2011:156869. doi: $10.1155 / 2011 / 156869$

Oostenveld, R., and Praamstra, P. (2001). The five percent electrode system for high-resolution EEG and ERP measurements. Clin. Neurophysiol. 112, 713-719. doi: 10.1016/s1388-2457(00)00527-7

Oppenheim, G. M., Dell, G. S., and Schwartz, M. F. (2010). The dark side of incremental learning: a model of cumulative semantic interference during lexical access in speech production. Cognition 114, 227-252. doi: 10.1016/j. cognition.2009.09.007

Pascual-Marqui, R. D., Michel, C. M., and Lehmann, D. (1995). Segmentation of brain electrical activity into microstates: model estimation and validation. IEEE Trans. Biomed. Eng. 42, 658-665. doi: 10.1109/10.391164

Perret, C., and Laganaro, M. (2012). Comparison of electrophysiological correlates of writing and speaking: a topographic ERP analysis. Brain Topogr. 25, 64-72. doi: 10.1007/s10548-011-0200-3

Perrin, F., Bertrand, O., and Pernier, J. (1987). Scalp current density mapping: value and estimation from potential data. IEEE Trans. Biomed. Eng. 34, 283-288. doi: 10.1109/TBME.1987.326089

Piai, V., Roelofs, A., Jensen, O., Schoffelen, J.-M., and Bonnefond, M. (2014a). Distinct patterns of brain activity characterise lexical activation and competition in spoken word production. PLoS One 9:e88674. doi: 10.1371/journal.pone.0088674

Piai, V., Roelofs, A., and Maris, E. (2014b). Oscillatory brain responses in spoken word production reflect lexical frequency and sentential constraint. Neuropsychologia 53, 146-156. doi: 10.1016/j.neuropsychologia.2013. 11.014

Piai, V., Roelofs, A., Rommers, J., and Maris, E. (2015). $\beta$ oscillations reflect memory and motor aspects of spoken word production: $\beta$ Oscillations in Word Production. Hum. Brain Mapp. 36, 2767-2780. doi: 10.1002/hbm. 22806

Piai, V., Roelofs, A., and van der Meij, R. (2012). Event-related potentials and oscillatory brain responses associated with semantic and Stroop-like interference effects in overt naming. Brain Res. 1450, 87-101. doi: 10.1016/j. brainres.2012.02.050

Protopapas, A. (2007). Check Vocal: a program to facilitate checking the accuracy and response time of vocal responses from DMDX. Behav. Res. Methods 39, 859-862. doi: 10.3758/bf03192979

Python, G., Fargier, R., and Laganaro, M. (2018). ERP evidence of distinct processes underlying semantic facilitation and interference in word production. Cortex 99, 1-12. doi: 10.1016/j.cortex.2017. 09.008

R Development Core Team. (2003). R: A Language and Environment for Statistical Computing. Vienna: R Foundation for Statistical Computing.

Roelofs, A. (1992). A spreading-activation theory of lemma retrieval in speaking. Cognition 42, 107-142. doi: 10.1016/0010-0277(92)90041-f 
Roelofs, A. (2003). Goal-referenced selection of verbal action: modeling attentional control in the Stroop task. Psychol. Rev. 110, 88-125. doi: 10.1037/0033-295x. 110.1 .88

Roelofs, A. (2006). Context effects of pictures and words in naming objects, reading words, and generating simple phrases. Q. J. Exp. Psychol. 59, 1764-1784. doi: 10.1080/17470210500416052

Roelofs, A., and Shitova, N. (2017). Importance of response time in assessing the cerebral dynamics of spoken word production: comment on Munding et al. (2016). Lang. Cogn. Neurosci. 32, 1064-1067. doi: 10.1080/ 23273798.2016.1274415

Rosinski, R. R. (1977). Picture-word interference is semantically based. Child Dev. 48, 643-647. doi: 10.2307/1128667

Rosinski, R. R., Golinkoff, R. M., and Kukish, K. S. (1975). Automatic semantic processing in a picture-word interference task. Child Dev. 46, 247-253. doi: 10.1111/j.1467-8624.1975.tb03301.x

Sailor, K., and Brooks, P. J. (2014). Do part-whole relations produce facilitation in the picture-word interference task? Q. J. Exp. Psychol. 67, 1768-1785. doi: 10.1080/17470218.2013.870589

Sailor, K., Brooks, P. J., Bruening, P. R., Seiger-Gardner, L., and Guterman, M. (2009). Exploring the time course of semantic interference and associative priming in the picture-word interference task. Q. J. Exp. Psychol. 62, 789-801. doi: 10.1080/17470210802254383

Schriefers, H., Meyer, A. S., and Levelt, W. J. M. (1990). Exploring the time course of lexical access in language production: picture-word interference studies. J. Mem. Lang. 29, 86-102. doi: 10.1016/0749-596x(90) 90011-n

Shitova, N., Roelofs, A., Schriefers, H., Bastiaansen, M., and Schoffelen, J.-M. (2016). Using brain potentials to functionally localise stroop-like effects in colour and picture naming: perceptual encoding versus word planning. PLoS One 11:e0161052. doi: 10.1371/journal.pone.0161052

Starreveld, P. A., and La Heij, W. (1995). Semantic interference, orthographic facilitation, and their interaction in naming tasks. J. Exp. Psychol. Learn. Mem. Cogn. 21, 686-698. doi: 10.1037/0278-7393.21.3.686

Starreveld, P. A., and La Heij, W. (1996). Time-course analysis of semantic and orthographic context effects in picture naming. J. Exp. Psychol. Learn. Mem. Cogn. 22, 896-918. doi: 10.1037/0278-7393.22.4.896
Starreveld, P. A., and La Heij, W. (2017). Picture-word interference is a Stroop effect: a theoretical analysis and new empirical findings. Psychon. Bull. Rev. 24, 721-733. doi: 10.3758/s13423-016-1167-6

Strijkers, K., Costa, A., and Thierry, G. (2010). Tracking lexical access in speech production: electrophysiological correlates of word frequency and cognate effects. Cereb. Cortex 20, 912-928. doi: 10.1093/cercor/bhp153

Valente, A., Bürki, A., and Laganaro, M. (2014). ERP correlates of word production predictors in picture naming: a trial by trial multiple regression analysis from stimulus onset to response. Front. Neurosci. 8:390. doi: 10.3389/fnins.2014. 00390

Vihla, M., Laine, M., and Salmelin, R. (2006). Cortical dynamics of visual/semantic vs. phonological analysis in picture confrontation. Neuroimage 33, 732-738. doi: 10.1016/j.neuroimage.2006.06.040

Vitkovitch, M., and Tyrrell, L. (1999). The effects of distractor words on naming pictures at the subordinate level. Q. J. Exp. Psychol. A 52, 905-926. doi: 10.1080/027249899390864

Wong, A. W.-K., Chiu, H.-C., Wang, J., Cao, J., Wong, S.-S., and Chen, H.-C. (2017). An early locus of associative and categorical context effects in speech production: evidence from an ERP study using the picture-word interference paradigm. Lang. Cogn. Neurosci. 32, 1305-1319. doi: 10.1080/23273798.2017. 1355060

Zhang, Q., Feng, C., Zhu, X., and Wang, C. (2016). Transforming semantic interference into facilitation in a picture-word interference task. Appl. Psycholinguist. 37, 1025-1049. doi: 10.1017/s014271641500034x

Conflict of Interest Statement: The authors declare that the research was conducted in the absence of any commercial or financial relationships that could be construed as a potential conflict of interest.

Copyright (C) 2018 Python, Fargier and Laganaro. This is an open-access article distributed under the terms of the Creative Commons Attribution License (CC BY). The use, distribution or reproduction in other forums is permitted, provided the original author(s) and the copyright owner are credited and that the original publication in this journal is cited, in accordance with accepted academic practice. No use, distribution or reproduction is permitted which does not comply with these terms. 